\title{
Decontamination of water polluted with pesticide using biopolymers: Adsorption of glyphosate by chitin and chitosan
}

\author{
Lama Rissouli $^{1,2,}$ Mohamed Benicha ${ }^{1}$, Tarik Chafik ${ }^{2}$, Mohamed Chabbi ${ }^{2}$
}

\author{
1 Laboratoire de résidus de pesticides, Unité de Recherche sur les Techniques Nucléaires, l'Environnement et la Qualité, INRA \\ de Tanger, Maroc \\ 2 Laboratoire de Génie de Matériaux et Valorisation des Ressources (LGVR)UAE/LO1FST, Faculté de Sciences et Techniques \\ de Tanger, Université Abdel Malek ESSAADI, Maroc.
}

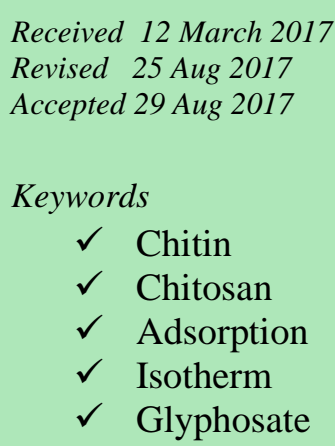

lamarissouli@gmail.com

\begin{abstract}
This present work focus on the efficiency of chitin and chitosan with respect to herbicide glyphosate adsorption under different experimental conditions, such as $\mathrm{pH}$, contact time and pesticide concentration. Adsorption characteristics were obtained from experimental isotherms that were confronted to Langmuir and Freundlich models. It was found that glyphosate adsorption was likely fitted by Langmuir model giving the maximal adsorbed amount within monolayer. Adsorption was most effective within the $\mathrm{pH}$ ranging from 3.76 to 5.04. On the other hand, desorption experiments show a maximum recovery of $63.76 \%$ for chitin and $9.67 \%$ for chitosan.
\end{abstract}

\section{Introduction}

Glyphosate or N-phosphonomethyl glycine is an organic acid with three polar functional groups (NH, COOH and $\mathrm{PO}_{3} \mathrm{H}_{2}$ ), known as a non-selective herbicide used in agriculture against many weeds [1, 2]. Nevertheless, the worldwide use of this herbicide requires particular attention regarding its harmful effects on environment and human beings associated with teratogenesis, carcenogenesis, mutagenesis and other developmental effects that are well reported in literature $[3,4,5]$. The main concern is related with its higher solubility in water that isreported to be responsible of both ground and surface water contamination [6, 7]. Therefore, adsorption process is known as one of the most inexpensive and reliable methods for pesticides removal from wastewater $[8,9]$. This process can be carried out using available and renewable natural material such as nitrogenous polysaccharide known as chitosan and its derivatives. The latters are produced from chitin, which is a natural carbohydrate polymer found in the skeleton of crustaceans [8]. Thus, the present study is devoted to the investigation of glyphosate removal from aqueous solutions using chitin and chitosan based adsorbent. Particular attention is given to the optimization of operating parameters affecting the adsorption process such as adsorbent amount, glyphosate concentration, contact time and $\mathrm{pH}$.

\section{NOMENCLATURE}

Qe-amount of glyphosate adsorbed at equilibrium (mg/g).V- Volume of glyphosate solution (L).

Co-initial glyphosate concentration $(\mathrm{mg} / \mathrm{L})$ m- Mass of adsorbent used in $(\mathrm{g})$

Ce- equilibrium solution concentration $(\mathrm{mg} / \mathrm{L})$ b- Langmuir constant.

Qm-maximum amount of glyphosate adsorbed in a monolayer $(\mathrm{mg} / \mathrm{g}) . \mathrm{K}$ and $\mathrm{n}$ - constants that estimate the adsorptionQ-

the amount of pesticide per unit mass of adsorbent $(\mathrm{mg} / \mathrm{g})$. capacity and intensity.

$\mathrm{R}_{\mathrm{L}}$ - indicates the shape of the isotherm 


\section{Materials and methods}

\subsection{Preparation of Chitosan}

The shrimp shells were obtained from North Moroccan sea, were washed, desiccated, cut and dried. Demineralization step was carried out using $0.55 \mathrm{M}$ hydrochloric acid baths. The demineralized shell was deproteinized by $0.3 \mathrm{M}$ sodium hydroxide [8]. The conversion of chitin to chitosan was achieved through deacetylation using the process suggested by Kurita [10]. The samples of chitin and chitosan were characterized by JASCO FT/IR- 410 infrared spectrophotometer.

The degree of Desacétylation (DDA) of shrimp chitosan was calculated by Baxter's [11] equation:

\section{$\mathrm{DDA}=70.26 \%$}

\subsection{Quantification of glyphosate and calibration curve}

A stock solution $(50 \mathrm{mg} / \mathrm{L})$ of glyphosate (Analytical grade glyphosate) was used to prepare eight samples containing different concentrations of the herbicide $(1,5,10,15,20,25,30$, and $35 \mathrm{mg} / \mathrm{mL})$, then transferred into a series of $10 \mathrm{ml}$ volumetric flasks, $1.0 \mathrm{ml}$ of $5 \%$ ninhydrin solution and $1.0 \mathrm{ml}$ of $5 \%$ sodium molybdate solution were addedto each of the tubes. The mixtures were placed in a water bath at temperature of $90-100^{\circ} \mathrm{C}$ for $10 \mathrm{~min}$ and made up to $10 \mathrm{~mL}$ in volumetric flasks in order to carry out the reactions path shown in (Figure1). The reading was then performed by JANWAY 6305 UV-VI spectrophotometer at $570 \mathrm{~nm}$ [12].
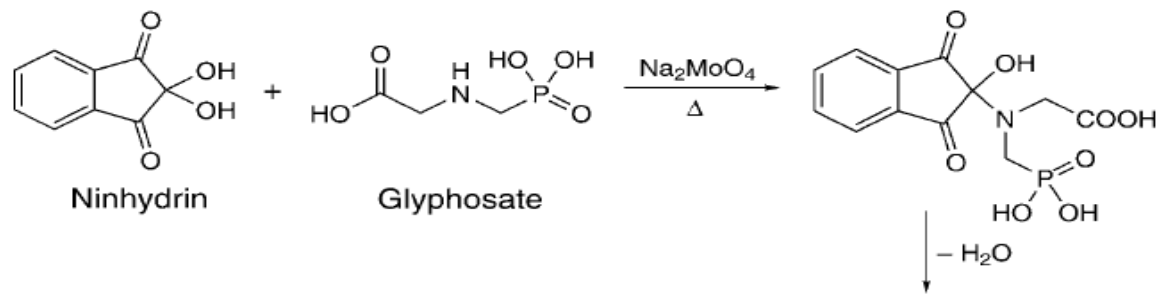

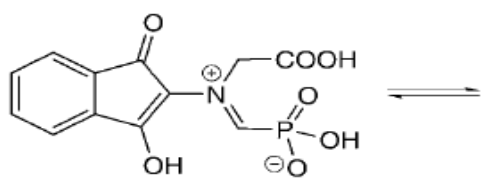

Purple color dye III

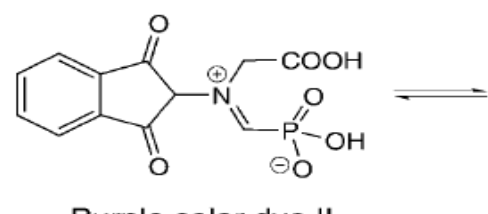

Purple color dye II<smiles>O=C(O)CN(CP(=O)(O)O)C1C(=O)c2ccccc2C1=O</smiles>

Purple color dye I

Figure 1: Proposed reaction path of glyphosate with ninhydrin in the presence of sodium molybdate [12].

\subsection{Adsorption and desorption experiments}

Adsorption and desorption experiments were carried out with model aqueous solution containing different concentration of glyphosate. The adsorption experiments were performed with $16 \mathrm{mg}$ samples of chitin and chitosan, using $10 \mathrm{mg} / \mathrm{L}$ solutions of glyphosate $(10 \mathrm{~mL})$ placed in $15 \mathrm{~mL}$ centrifuge tubes. The tubes were shook on an orbital shaker at $300 \mathrm{rpm}$ and $18{ }^{\circ} \mathrm{C}$. Aliquots $(1 \mathrm{~mL})$ of the aqueous solution were removed every $60 \mathrm{~min}$ for quantification of the herbicide using JANWAY 6305 UV-VI spectrophotometer, after which the adsorption kinetics curves were constructed. All the experiments were performed in triplicate.

The effect of glyphosate concentration was studied with series of $15 \mathrm{~mL}$ centrifuge tubes containing $10 \mathrm{ml}$ of glyphosate solution for various concentrations ranging from $1 \mathrm{mg} / \mathrm{l}$ to $30 \mathrm{mg} / \mathrm{l}$. The effect of $\mathrm{pH}$ was also examined by changing the $\mathrm{pH}$ of the mentioned solution for values ranging from 3.09 to 9.81 adjusted by addition of $0.01 \mathrm{M} \mathrm{NaOH}$ or $0.05 \mathrm{M} \mathrm{HCl}$. The effect of temperature was evaluated using a series of $15 \mathrm{~mL}$ centrifuge tubes containing $10 \mathrm{~mL}$ of glyphosate solution at a concentration of $10 \mathrm{mg} / \mathrm{L}$ at different temperature values $\left(18,28\right.$ and $\left.38^{\circ} \mathrm{C}\right)$. The quantity of glyphosate adsorbed was determined by the following equation [13]:

$$
Q e=\frac{(C o-C e) \times V}{m}
$$

Desorption experiments were carried out with the chitin and chitosan samples used in the adsorption process, as follows : chitin and chitosan are placed in $15 \mathrm{~mL}$ centrifuge tubes containing $10 \mathrm{~mL}$ of distilled water, then shaked and undertaked at the same periods of adsorption experiments. The extent of desorption was calculated from the following expression:

$$
\text { Desorption } \%=\frac{\text { desorbed amounts of glyphosate }}{\text { adsorbed amount of glyphosate }} * 100
$$




\section{Results and discussion}

\subsection{Effect of contact time on adsorption capacity}

The nature of the adsorption of glyphosate on adsorbents is illustrated in figure 2. glyphosate is adsorbed during the first hours of agitation, This is due to the interaction between the anionic form of glyphosate and the cationic form of biopolymers. The adsorption equilibrium is reached following a contact time of $8 \mathrm{~h}$ and $6 \mathrm{~h}$ for chitin and chitosan respectively, as indicated by no modification in the adsorbed amount because of the saturation of active sites of adsorbents, which leads to the repulsion between glyphosate and chitosan which become negatively charged with the amine, carboxylic and phosphoric acid [14], leading to adsorption capacities $77 \%$ and $92 \%$ for chitin and chitosanrespectively.

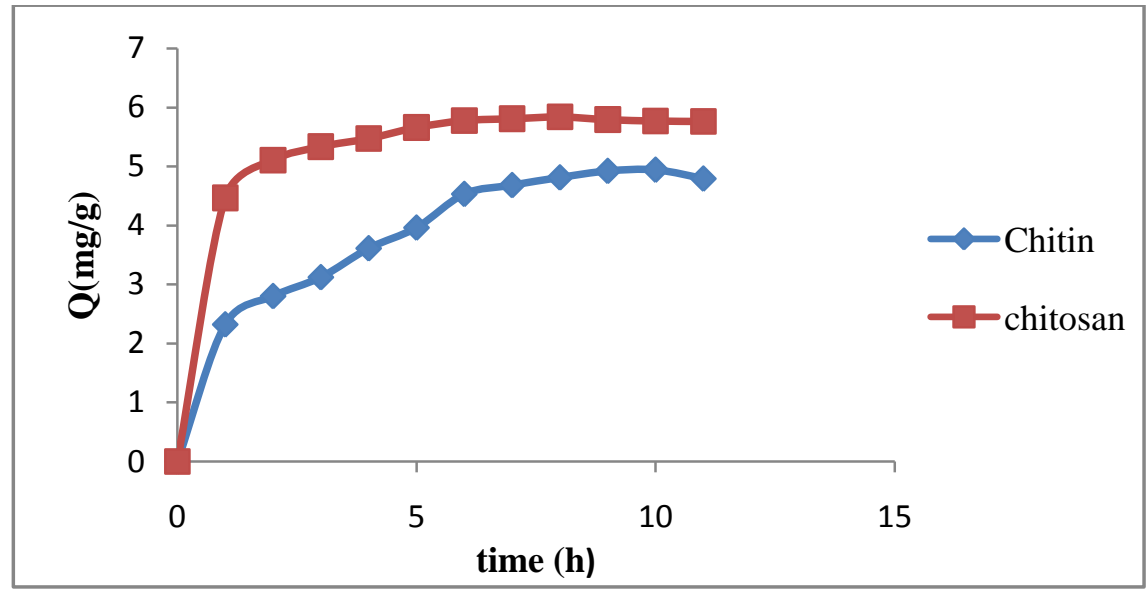

Figure 2: Effect of contact time on glyphosate adsorption.

\subsection{Adsorptions isotherms}

The adsorption isotherms of glyphosate on chitin and chitosan are shown in figure 3 . It is indicated that the glyphosate retention by chitin and chitosan was a L-type curve according to Giles classification [15], suggesting a high affinity of chitin and chitosan for this herbicide leading to a progressive saturation of the surface with glyphosate.

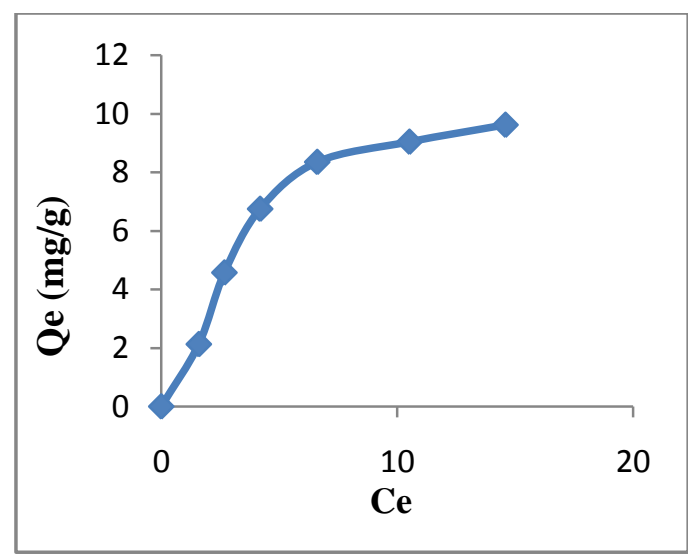

Figure3.a: chitin adsorption isotherm.

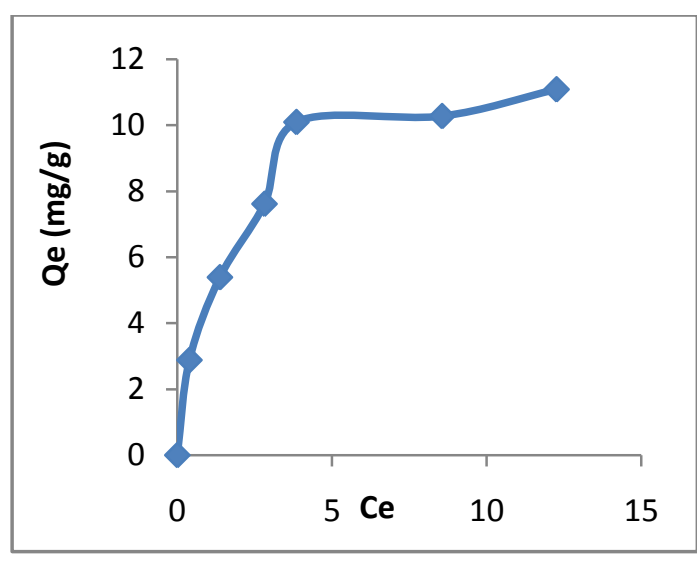

Figure3.b: chitosan adsorption isotherm.

On the other hand, the isotherm data for the adsorption of glyphosate on chitin and chitosan were confronted with linearized form of Langmuir model[16]:

$$
\frac{C e}{Q e}=\frac{C e}{Q m}+\frac{1}{b Q m}
$$

The data were also confronted with linearized form of Freundlich model $[15,16]$ :

$$
\log Q=\log k+\frac{1}{n} \log C e
$$


The calculated results of the Langmuir and Freundlich isotherm constants are given in table 1. It is found that adsorption of glyphosate on chitin and chitosan were correlated well with Langmuir equation as compared to Freundlich equation under the concentration range studied (figure 4).

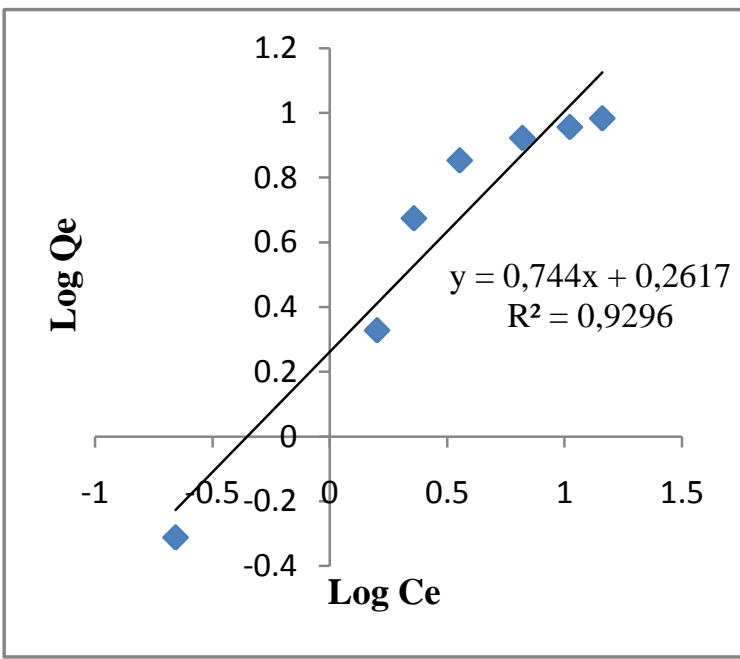

Figure 4.c: Freundlich isotherm for adsorption by chitin

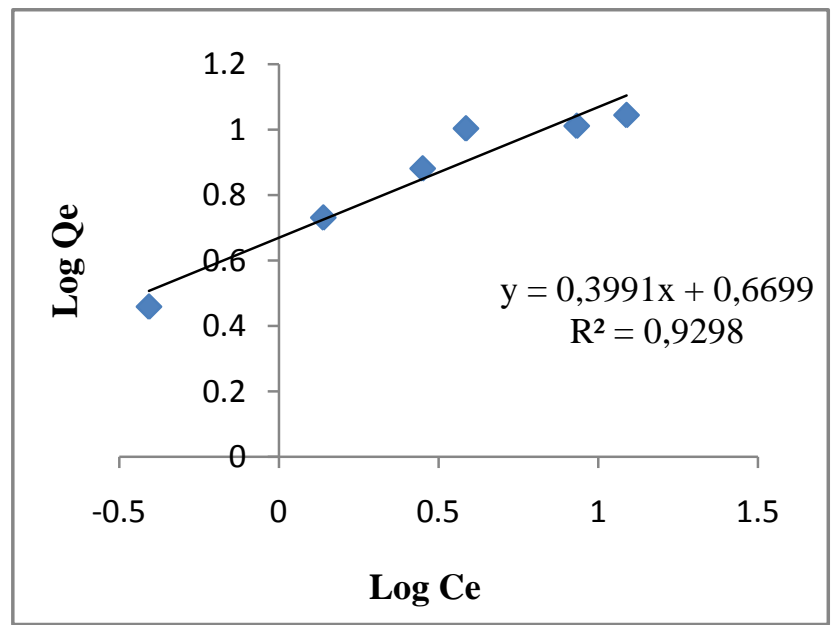

Figure 4.c: Freundlich isotherm for adsorption by chitosan

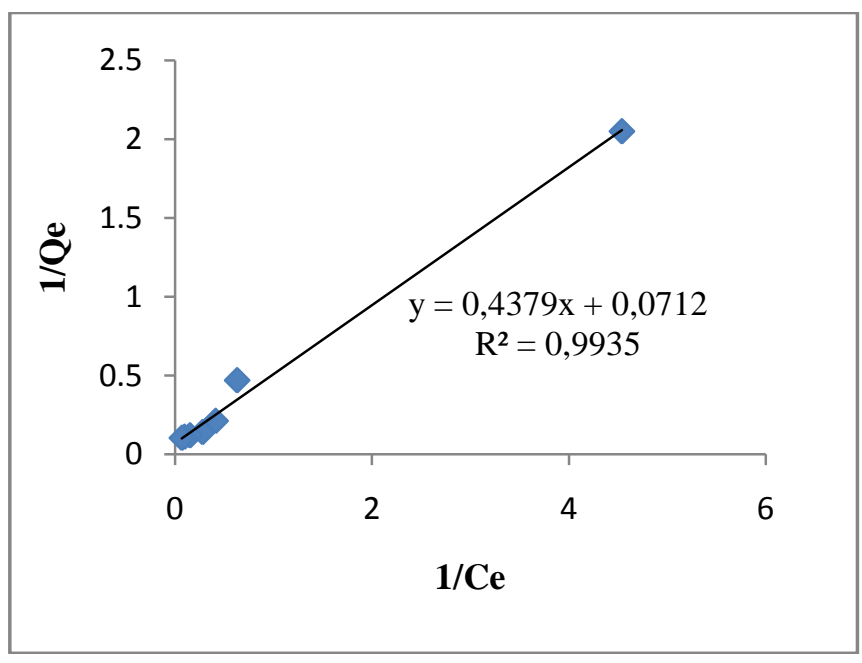

Figure 4.d: Langmuir isotherm for glyphosate adsorption by chitin

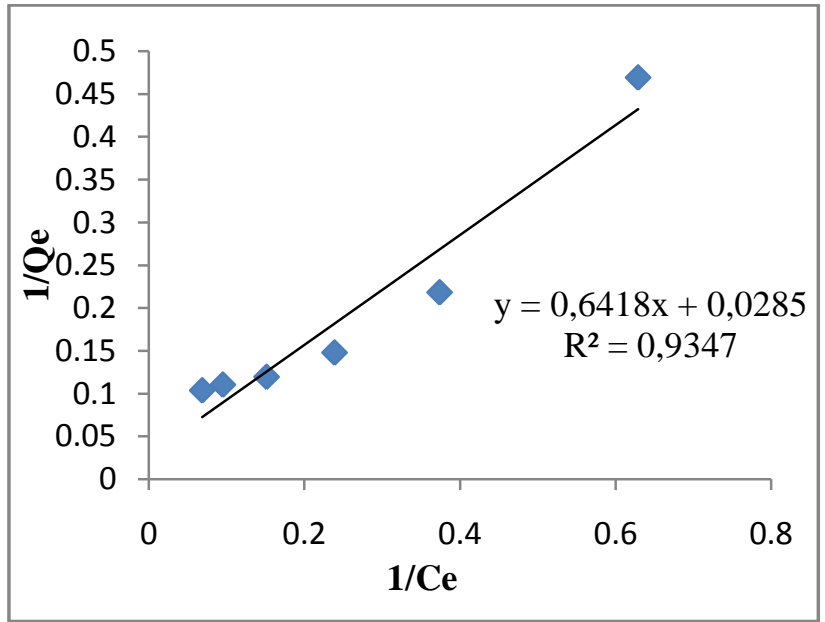

Figure 4.d: Langmuir isotherm for glyphosate adsorption by chitosan

Table1: Isotherm parameters for glyphosate adsorption by chitin and chitosan.

\begin{tabular}{lllllll}
\hline \multirow{2}{*}{ Polymers } & Langmuir & \multicolumn{5}{c}{ Freundlich } \\
\cline { 2 - 7 } & $\mathrm{Q}_{\max }$ & $\mathrm{b}$ & $\mathrm{R}^{2}$ & $1 / \mathrm{n}$ & $\mathrm{K}$ & $\mathrm{R}^{2}$ \\
\hline Chitin & 14,04 & 0,162 & 0,993 & 0,744 & 1,82 & 0,929 \\
\hline Chitosan & 35,08 & 0,044 & 0,934 & 0,3991 & 4,67 & 0,897 \\
\hline
\end{tabular}

The main characteristics of the Langmuir isotherm can be expressed by a dimension less constant separation factor or equilibrium parameter $\mathrm{R}_{\mathrm{L}}$, which is given by the following expression:

$$
R_{L}=\frac{1}{(1+b C o)}
$$


The value of $R_{L}$ indicates the shape of the isotherm to be either unfavorable $\left(R_{L}>1\right)$ or linear $\left(R_{L}=1\right)$ or favorable $\left(0<\mathrm{R}_{\mathrm{L}}<1\right)$ or irreversible $\left(\mathrm{R}_{\mathrm{L}}=0\right)$ [17].

$\mathrm{R}_{\mathrm{L}}$ values for chitin $(0.170-0.860)$ and chitosan $(0.86-0.93)$ indicate that glyphosate uptake is favorable using these two adsorbents.

\subsection{Effect of $p H$}

The $\mathrm{pH}$ of solution containing $10 \mathrm{mg} / \mathrm{l}$ of glyphosate is 4.57 , attributed to the presence of carboxylic functions, amine and phosphonate group in the molecules of pesticide. The effect of changing the solution $\mathrm{pH}$ on the adsorption capacity of glyphosate is shown in Figure 5. The experiments indicated that the highest adsorption values on chitin and chitosan were obtained for $\mathrm{pH}$ ranging between 3.76 and 5.04. This means that adsorption of this molecule is enhanced in acidic environment, this finding is apparently attributed to the protonation of amino groups and chitosan becomes positively charged. So, this yield to a strong electrostatic interaction between $-\mathrm{NH}_{3}{ }^{+}$group of chitosan and pesticide anion. The chitin contains amide group - $\mathrm{CO}-\mathrm{NH}-$, which cannot be easily protonated in acidic solutions. The lone pairs in the glyphosate molecule will be attracted to the positive charges on the adsorbents. Since the electron with drawal by carbonyl group makes the nitrogen of the amide group a much poorer source of electrons than those provided by amine group. This explains the lower adsorption capacity of chitin due to the lower of electrostatic interaction between chitin and pesticide anions [18]. At $\mathrm{pH}<$ 4.4 the reduced amount can be explained by the repulsion between cationic adsorbent and adsorbate, due to the $\mathrm{HCl}$ acid reaction with glyphosate and chitosan.

In the case of solution with $\mathrm{pH} 5.042<\mathrm{pH}<8$ with lower concentration of $\mathrm{H}^{+}$, as a result, the adsorption of glyphosate decreases with increasing $\mathrm{pH}$ solution as shown in Figure 5. Whereas at $\mathrm{pH}$ higher than 8, chitosan showed very low amount of adsorbed glyphosate. This is due to the increase concentration of hydroxide ions in the solution, causing deprotonation of the amino groups in chitosan. This results demonstrates the repulsive effect between deprotonated amino group of chitosan with carboxylic function and phosphonyl groups in glyphosate, hence the adsorption capacity was greatly reduced. At $\mathrm{pH}>10$ and $\mathrm{pH}<3$, chitosan gets precipitated and forms gels.

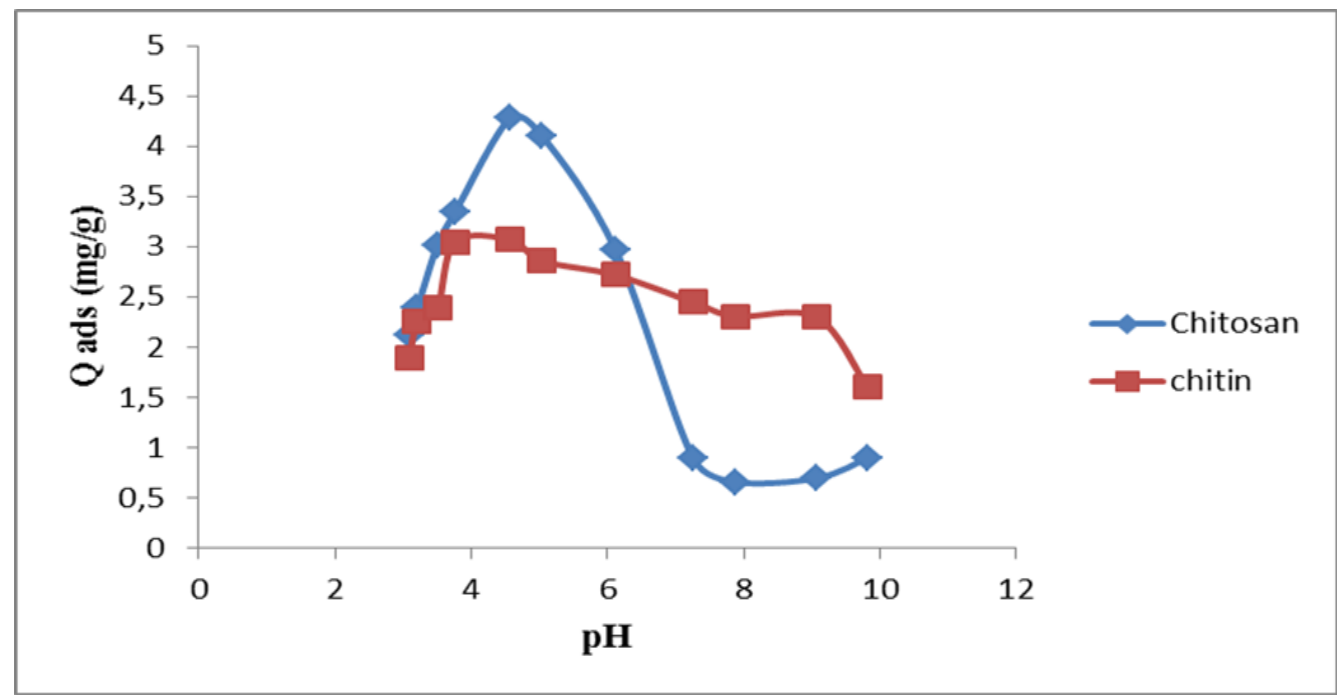

Figure 5: Effect of $\mathrm{pH}$ on adsorption of glyphosate.

\subsection{Desorption kinetic}

After desorption step, desorption kinetics were determined (figure 6). The desorption of glyphosate from a chitin and chitosan was $63.76 \%$ and $9.67 \%$ respectively; the desorption capacity of chitosan was poorer than chitin. It due to the strong electrostatic interactions created between glyphosate and amino group of chitosan, which limited chitosan desorption. This result indicates that chitin can be used successfully after regeneration for the removal of glyphosate from wastewater. 


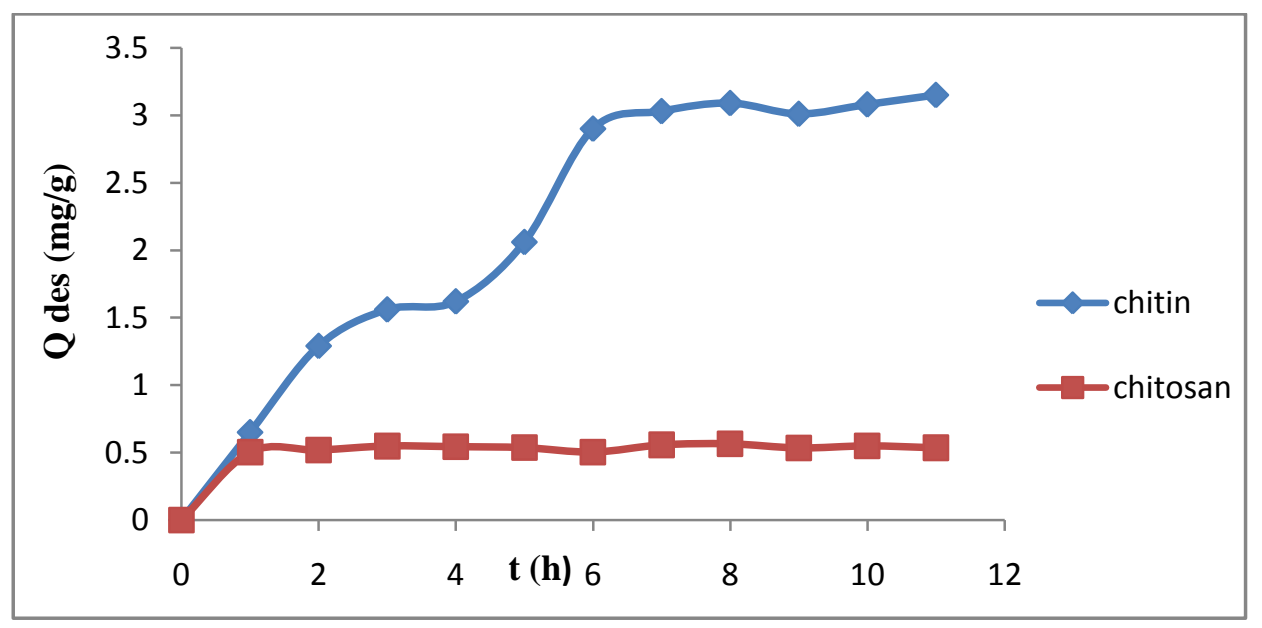

Figure 6: Kinetic desorption of glyphosate.

\section{Conclusion}

Based on the obtained result, the following conclusion could be drawn:

(i) The prepared chitin and chitosan samples were found to be efficient on glyphosate removal,

(ii) Langmuir isotherm was found to be more appropriate for the description adsorption behavior

(iii) The adsorption of glyphosate depends on $\mathrm{pH}$ and was found to be higher at acidic $\mathrm{pH}$.

(iv) Desorption experiments revealed that chitin can be regenerated and reused several times making the adsorption process more economical.

\section{References}

1. Daniele P.G., De Stefano C., Prenesti E.,Sammartano S., Talanta45 (1997) 425-431.

2. Williams G. M., Kroes R., Munro I.C., Regul. Toxicol. Pharmacol. 31 (2000) 117-165.

3. Ayoola S.O., African J. Agric. Res. 3 (2008) 825-834.

4. Conrad A., Schröter-Kermani C., Hoppe W., Rüther M., Pieper S., Kolossa-Gehring M., Inter. J. Hygiene and Environ Health (2017).

5. Arroyave J.M., Waiman C. P., Zanini J., Avena,.Chemosphere 145 (2016) 34-41.

6. Marouane B., Belhsain K., Jahdi M., El Hajjaji S., Dahchour A., Dousset S., Satrallah A., J. Mater. Environ. Sci. 5 (2014) 2151- 2155.

7. Benicha M., Mrabet R., Azmani A. J., J. Soil. Sci. Environ. Manag. 12 (2011) 404-410.

8. Rissouli L., Benicha M., Chabbi M., J. Mater. Environ. Sci.7 (2016) 530-541.

9. Xiao G., Wen R., Fluid Phase Equilibria411 (2016) 1-6.

10. Kurita K., Tomita K., Tada T., Ishii S., Nishimura S.I., Shimoda K., J. Polym. Sci. 31 (1993) 485- 491.

11. Kumaria S., Rath P., Kumar A., S., Tiwari T., N., Environ Technology \& Innovation 3 (2015) 77-85

12. Bhaskara B.L., Nagaraja P., Helvetica Chim. Acta 89 (2006) 2686-2693.

13. Motawie A. M., Mahmoud K., El-Sawy A., Kamal H. M., Hefni H., Ibrahiem H., Egyptian Journal of Petroleum (2014).

14. Carneiro R.T. A., Taketa T. B., Neto R.G., Oliveira J.L., Campos E.V.R., Mariana A. M., Silva C.M.G., Beppu M.M., Fraceto L.F., J. Environ.Manag.151 (2015) 353-360.

15. Giles C.H., McEwan T.H., Nakhw S.N., Smith D., J. Chem. Soc. 111 (1960) 3973-3993.

16. Aarfane A., Salhi A., El Krati M., Tahiri S., Monkade M., Lhadi E.K., Bensitel M., J. Mater. Environ. Sci. 5 (2014) 1927-1939.

17. Lazaridis N.K., Kyzas G.Z., Vassiliou A. A., BikiarisD. N., Langmuir 23 (2007)7634-7643.

18. Chiou L.M.S., Li H.Y., Chemosphere 50 (2003) 1095-1105.

\section{(2017); http://www.jmaterenvironsci.com}

